\title{
Science, technology and innovation in a 21st century context
}

\author{
John H. Marburger III
}

Published online: 27 August 2011

(C) Springer Science+Business Media, LLC. 2011

This editorial essay was prepared by John H. “Jack" Marburger for a workshop on the "science of science and innovation policy" held in 2009 that was the basis for this special issue. It is published posthumously.

Linking the words "science," "technology," and "innovation," may suggest that we know more about how these activities are related than we really do. This very common linkage implicitly conveys a linear progression from scientific research to technology creation to innovative products. More nuanced pictures of these complex activities break them down into components that interact with each other in a multi-dimensional socio-technologicaleconomic network. A few examples will help to make this clear.

Science has always functioned on two levels that we may describe as curiosity-driven and need-driven, and they interact in sometimes surprising ways. Galileo's telescope, the paradigmatic instrument of discovery in pure science, emerged from an entirely pragmatic tradition of lens-making for eye-glasses. And we should keep in mind that the industrial revolution gave more to science than it received, at least until the last half of the nineteenth century when the sciences of chemistry and electricity began to produce serious economic payoffs. The flowering of science during the era, we call the enlightenment owed much to its links with crafts and industry, but as it gained momentum science created its own need for practical improvements. After all, the frontiers of science are defined by the capabilities of instrumentation, that is, of technology. The needs of pure science are a huge but poorly understood stimulus for technologies that have the capacity to be disruptive precisely because these needs do not arise from the marketplace. The innovators who built the World Wide Web on the foundation of the Internet were particle physicists at CERN, struggling to satisfy their unique need to share complex information. Others soon discovered "needs" of which they had been unaware that could be satisfied by this innovation, and from that point the Web transformed the Internet from a tool for the technological elite into a broad platform for a new kind of economy.

John H. Marburger III—deceased

J. H. Marburger III ( $ه)$

Stony Brook University, Stony Brook, NY, USA 
Necessity is said to be the mother of invention, but in all human societies, "necessity" is a mix of culturally conditioned perceptions and the actual physical necessities of life. The concept of need, of what is wanted, is the ultimate driver of markets and an essential dimension of innovation. And as the example of the World Wide Web shows, need is very difficult to identify before it reveals itself in a mass movement. Why did I not know I needed a cell phone before nearly everyone else had one? Because until many others had one I did not, in fact, need one. Innovation has this chicken-and-egg quality that makes it extremely hard to analyze. We all know of visionaries who conceive of a society totally transformed by their invention and who are bitter that the world has not embraced their idea. Sometimes we think of them as crackpots, or simply unrealistic about what it takes to change the world. We practical people necessarily view the world through the filter of what exists, and fail to anticipate disruptive change. Nearly always we are surprised by the rapid acceptance of a transformative idea. If we truly want to encourage innovation through government policies, we are going to have to come to grips with this deep unpredictability of the mass acceptance of a new concept. Works analyzing this phenomenon are widely popular under titles like "The Tipping Point" by Gladwell (2000) or more recently the book by Taleb (2007) called The Black Swan, among others.

What causes innovations to be adopted and integrated into economies depends on their ability to satisfy some perceived need by consumers, and that perception may be an artifact of marketing, or fashion, or cultural inertia, or ignorance. Some of the largest and most profitable industries in the developed world-entertainment, automobiles, clothing and fashion accessories, health products, children's toys, grownups' toys!- depend on perceptions of need that go far beyond the utilitarian and are notoriously difficult to predict. And yet these industries clearly depend on sophisticated and rapidly advancing technologies to compete in the marketplace. Of course, they do not depend only upon technology. Technologies are part of the environment for innovation, or in a popular and very appropriate metaphor-part of the innovation ecology.

This complexity of innovation and its ecology is conveyed in Chapter One of a currently popular best-seller in the United States called Innovation Nation by the American innovation guru, Kao (2007), formerly on the faculty of the Harvard Business School:

"I define it [innovation]," writes Kao, "as the ability of individuals, companies, and entire nations to continuously create their desired future. Innovation depends on harvesting knowledge from a range of disciplines besides science and technology, among them design, social science, and the arts. And it is exemplified by more than just products; services, experiences, and processes can be innovative as well. The work of entrepreneurs, scientists, and software geeks alike contributes to innovation. It is also about the middlemen who know how to realize value from ideas. Innovation flows from shifts in mind-set that can generate new business models, recognize new opportunities, and weave innovations throughout the fabric of society. It is about new ways of doing and seeing things as much as it is about the breakthrough idea." (Kao 2007, p. 19).

This is not your standard government-type definition. Gurus, of course, do not have to worry about leading indicators and predictive measures of policy success. Nevertheless, some policy guidance can be drawn from this high level "definition," and I will do so later.

The first point, then, is that the structural aspects of "science, technology, and innovation" are imperfectly defined, complex, and poorly understood. There is still much work to do to identify measures, develop models, and test them against actual experience before we can say we really know what it takes to foster innovation. The second point I want to make is about the temporal aspects: all three of these complex activities are changing with 
time. Science, of course, always changes through the accumulation of knowledge, but it also changes through revolutions in its theoretical structure, through its ever-improving technology, and through its evolving sociology. The technology and sociology of science are currently impacted by a rapidly changing information technology. Technology today flows increasingly from research laboratories but the influence of technology on both science and innovation depends strongly on its commercial adoption, that is, on market forces. Commercial scale manufacturing drives down the costs of technology so it can be exploited in an ever-broadening range of applications. The mass market for precision electro-mechanical devices like cameras, printers, and disk drives is the basis for new scientific instrumentation and also for further generations of products that integrate hundreds of existing components in new devices and business models like the Apple iPod and video games, not to mention improvements in old products like cars and telephones. Innovation is changing too as it expands its scope beyond individual products to include all or parts of systems such as supply chains and inventory control, as in the Wal-Mart phenomenon. Apple's iPod does not stand alone; it is integrated with iTunes software and novel arrangements with media providers.

With one exception, however, technology changes more slowly than it appears because we encounter basic technology platforms in a wide variety of relatively short-lived products. Technology is like a language that innovators use to express concepts in the form of products, and business models that serve (and sometimes create) a variety of needs, some of which fluctuate with fashion. The exception to the illusion of rapid technology change is the pace of information technology, which is no illusion. It has fulfilled Moore's Law for more than half a century, and it is a remarkable historical anomaly arising from the systematic exploitation of the understanding of the behavior of microscopic matter following the discovery of quantum mechanics. The pace would be much less without a continually evolving market for the succession of smaller, higher capacity products. It is not at all clear that the market demand will continue to support the increasingly expensive investment in fabrication equipment for each new step up the exponential curve of Moore's Law. The science is probably available to allow many more capacity doublings if markets can sustain them. Let me digress briefly on this point.

Many science commentators have described the twentieth century as the century of physics and the twenty-first as the century of biology. We now know that is misleading. It is true that our struggle to understand the ultimate constituents of matter has now encompassed (apparently) everything of human scale and relevance, and that the universe of biological phenomena now lies open for systematic investigation and dramatic applications in health, agriculture, and energy production. But there are two additional frontiers of physical science, one already highly productive, the other very intriguing. The first is the frontier of complexity, where physics, chemistry, materials science, biology, and mathematics all come together. This is where nanotechnology and biotechnology reside. These are huge fields that form the core of basic science policy in most developed nations. The basic science of the twenty-first century is neither biology nor physics, but an interdisciplinary mix of these and other traditional fields. Continued development of this domain contributes to information technology and much else. I mentioned two frontiers. The other physical science frontier borders the nearly unexploited domain of quantum coherence phenomena. It is a very large domain and potentially a source of entirely new platform technologies not unlike microelectronics. To say more about this would take me too far from our topic. The point is that nature has many undeveloped physical phenomena to enrich the ecology of innovation and keep us marching along the curve of Moore's Law if we can afford to do so. 
I worry about the psychological impact of the rapid advance of information technology. I believe it has created unrealistic expectations about all technologies and has encouraged a casual attitude among policy makers toward the capability of science and technology to deliver solutions to difficult social problems. This is certainly true of what may be the greatest technical challenge of all time - the delivery of energy to large developed and developing populations without adding greenhouse gases to the atmosphere. The challenge of sustainable energy technology is much more difficult than many people currently seem to appreciate. I am afraid that time will make this clear.

Structural complexities and the intrinsic dynamism of science and technology pose challenges to policy makers, but they seem almost manageable compared with the challenges posed by extrinsic forces. Among these are globalization and the impact of global economic development on the environment. The latter, expressed quite generally through the concept of "sustainability" is likely to be a component of much twenty-first century innovation policy. Measures of development, competitiveness, and innovation need to include sustainability dimensions to be realistic over the long run. Development policies that destroy economically important environmental systems, contribute to harmful global change, and undermine the natural resource basis of the economy are bad policies. Sustainability is now an international issue because the scale of development and the globalization of economies have environmental and natural resource implications that transcend national borders.

From the policy point of view, globalization is a not a new phenomenon. Science has been globalized for centuries, and we ought to be studying it more closely as a model for effective responses to the globalization of our economies. What is striking about science is the strong imperative to share ideas through every conceivable channel to the widest possible audience. If you had to name one chief characteristic of science, it would be empiricism. If you had to name two, the other would be open communication of data and ideas. The power of open communication in science cannot be overestimated. It has established, uniquely among human endeavors, an absolute global standard. And it effectively recruits talent from every part of the globe to labor at the science frontiers. The result has been an extraordinary legacy of understanding of the phenomena that shape our existence. Science is the ultimate example of an open innovation system.

Science practice has received much attention from philosophers, social scientists, and historians during the past half-century, and some of what has been learned holds valuable lessons for policy makers. It is fascinating to me how quickly countries that provide avenues to advanced education are able to participate in world science. The barriers to a small but productive scientific activity appear to be quite low and whether or not a country participates in science appears to be discretionary. A small scientific establishment, however, will not have significant direct economic impact. Its value at early stages of development is indirect, bringing higher performance standards, international recognition, and peer role models for a wider population. A science program of any size is also a link to the rich intellectual resources of the world scientific community. The indirect benefit of scientific research to a developing country far exceeds its direct benefit, and policy needs to recognize this. It is counterproductive to base support for science in such countries on a hoped-for direct economic stimulus.

Keeping in mind that the innovation ecology includes far more than science and technology, it should be obvious that within a small national economy innovation can thrive on a very small indigenous science and technology base. But innovators, like scientists, do require access to technical information and ideas. Consequently, policies favorable to innovation will create access to education and encourage free communication 
with the world technical community. Anything that encourages awareness of the marketplace and all its actors on every scale will encourage innovation.

This brings me back to John Kao's definition of innovation. His vision of "the ability of individuals, companies, and entire nations to continuously create their desired future" implies conditions that create that ability, including most importantly educational opportunity (Kao 2007, p. 19). The notion that "innovation depends on harvesting knowledge from a range of disciplines besides science and technology" implies that innovators must know enough to recognize useful knowledge when they see it, and that they have access to knowledge sources across a spectrum that ranges from news media and the Internet to technical and trade conferences (2007, p. 19). If innovation truly "flows from shifts in mind-set that can generate new business models, recognize new opportunities, and weave innovations throughout the fabric of society," then the fabric of society must be somewhat loose-knit to accommodate the new ideas (2007, p. 19). Innovation is about risk and change, and deep forces in every society resist both of these. A striking feature of the US innovation ecology is the positive attitude toward failure, an attitude that encourages risk-taking and entrepreneurship.

All this gives us some insight into what policies we need to encourage innovation. Innovation policy is broader than science and technology policy, but the latter must be consistent with the former to produce a healthy innovation ecology. Innovation requires a predictable social structure, an open marketplace, and a business culture amenable to risk and change. It certainly requires an educational infrastructure that produces people with a global awareness and sufficient technical literacy to harvest the fruits of current technology. What innovation does not require is the creation by governments of a system that defines, regulates, or even rewards innovation except through the marketplace or in response to evident success. Some regulation of new products and new ideas is required to protect public health and environmental quality, but innovation needs lots of freedom. Innovative ideas that do not work out should be allowed to die so the innovation community can learn from the experience and replace the failed attempt with something better.

Do we understand innovation well enough to develop policy for it? If the policy addresses very general infrastructure issues such as education, economic, and political stability and the like, the answer is perhaps. If we want to measure the impact of specific programs on innovation, the answer is no. Studies of innovation are at an early stage where anecdotal information and case studies, similar to John Kao's book-or the books on Business Week's top ten list of innovation titles-are probably the most useful tools for policy makers.

I have been urging increased attention to what I call the science of science policy-the systematic quantitative study of the subset of our economy called science and technology-including the construction and validation of micro- and macro-economic models for S\&T activity. Innovators themselves, and those who finance them, need to identify their needs and the impediments they face. Eventually, we may learn enough to create reliable indicators by which we can judge the health of our innovation ecosystems. The goal is well worth the sustained effort that will be required to achieve it.

\section{References}

Gladwell, M. (2000). The tipping point: How little things can make a big difference. Boston: Little, Brown and Company.

Kao, J. (2007). Innovation nation: How America is losing its innovation edge, why it matters, and what we can do to get it back. New York: Free Press.

Taleb, N. N. (2007). The black swan: The impact of the highly improbable. New York: Random House. 